\title{
Low-Grade Appendiceal
}

\section{Mucinous Neoplasm Presenting as a Surgical Emergency: A Case Report}

\author{
Evangelos Athanassiou ${ }^{a}$ Michail Spyridakis ${ }^{a}$ \\ Fotini Karasavvidou $^{b}$ Dimitra Vamvakopoulou ${ }^{\mathrm{a}}$ \\ Evangelia Karaiskou ${ }^{d}$ Nikolaos Vamvakopoulos ${ }^{c}$ \\ Paraskevi Theodosiou ${ }^{b}$ Constantinos Hatzitheofilou ${ }^{a}$ \\ Departments of aSurgery, ${ }^{\mathrm{b} P a t h o l o g y, ~ a n d ~ ' B i o l o g y, ~ U n i v e r s i t y ~ o f ~ T h e s s a l y, ~}$ \\ Thessaly, and dDepartment of Radiology, County Hospital of Larissa, Larissa, \\ Greece
}

\section{Key Words}

Low-grade appendiceal tumor - Acute abdomen

\begin{abstract}
We present the case of a female patient admitted to our University Hospital with acute abdominal pain mimicking an intraperitoneal septic condition caused possibly by acute appendicitis. CT and ultrasound scan showed a mass situated in the right iliac fossa. The patient was submitted to laparotomy and right hemicolectomy. The operative findings were suggestive of an appendiceal mucocele. The histology report revealed a low-grade appendiceal mucinous neoplasm. The patient had no clinical, biochemical or visual signs of disease recurrence 6 months postoperatively.
\end{abstract}

\section{Introduction}

Tumors of the appendix are rare clinical entities occurring in less than $2 \%$ of all appendectomies [1]. Appendiceal tumors that can be confidently placed in the low-grade group and are confined to the appendix are considered clinically benign [2]. Frequently, these tumors are discovered incidentally either during a survey or at the time of surgery for other causes [3]. Their clinical significance lies with the possibility of rupture of the appendix and spillage of mucin into the peritoneal cavity resulting in pseudomyxoma peritonei, a complication that is followed by worse outcome than non-ruptured cases [4]. Thus, preoperative recognition of an appendiceal mucocele is important because a 
possible rupture of the organ is imminent before or even during surgery. Of those patients proved to have a mucocele during surgery, approximately $40 \%(13 / 37)$ have been diagnosed preoperatively as acute appendicitis on clinical grounds alone [5].

We report a low-grade appendiceal mucinous neoplasm referred to our department with the clinical picture of an acute abdomen with a palpable mass which was managed as a surgical emergency.

\section{Case Presentation}

A 69-year-old female patient was transferred to the University Hospital with acute severe right iliac fossa pain of $24 \mathrm{~h}$ duration and a fever of $37.5^{\circ} \mathrm{C}$. The pain was continuous and confined to the lower abdomen with no exacerbations or remissions. There was no radiation of pain; on admission it was located mainly in the hypogastrium and right iliac fossa. No history of aggravating or relieving factors was elicited. The patient had been experiencing vague lower abdominal pain for seven days before admission, but she had not visited her doctor until the pain turned severe. The patient had no anorexia, nausea, vomiting or weight loss. She had had hysterectomy and bilateral oophorectomy for a benign condition 15 years ago. On examination the general appearance of the patient was unaffected. The abdomen was not distended and no guarding or spasm was elicited. There was rebound tenderness and a tender mass was felt in the right iliac fossa on palpation. In the hospital where she was first admitted, the patient had routine blood tests done and plain X-rays of the abdomen (erect and supine) as well as a chest X-ray. At that time she was also submitted to a CT scan of the abdomen (fig. 1). An ultrasound scan was requested after she was admitted to our hospital.

\section{Preoperative Laboratory Findings}

\section{Hematology and Biochemistry Tests}

The hematology tests showed Hct $38.4 \mathrm{~g} / \mathrm{dl}$, WBC 12.6/ $\mu$ (78.4\% neutrophils), Hgb $13.2 \mathrm{~g} / \mathrm{dl}$, PLT $274,000 / \mathrm{mm}^{3}$. The biochemistry results showed blood sugar $126 \mathrm{mg} / \mathrm{dl}(75-115)$, urea $49 \mathrm{mg} / \mathrm{dl}(10-50)$, creatinine $0.90 \mathrm{mg} / \mathrm{dl}$ (0.66-1.09), total proteins $7.6 \mathrm{~g} / \mathrm{dl}$ (6.4-8.3), (albumin $4.40 \mathrm{~g} / \mathrm{dl}$ [3.5-5.2]), total bilirubin $0.91 \mathrm{mg} / \mathrm{dl}$ (up to 1.1), (direct bilirubin $0.19 \mathrm{mg} / \mathrm{dl}$ [0.01-0.4]), SGOT(AST) $18 \mathrm{IU} / \mathrm{l}$ (10-35), SGPT(ALT) 22 IU/1 (10-35), $\gamma$ GT 12 U/1 (9-35), ALP 40 IU/l (35-104), LDH 235 IU/l (135-225), serum amylase $51 \mathrm{U} / \mathrm{l}(0-90)$, potassium $4.2 \mathrm{mmol} / \mathrm{l}$ (3.5-5.3), sodium $140 \mathrm{mmol} / \mathrm{l}$ (135-153), and calcium 10.0 $\mathrm{mg} / \mathrm{dl}(8.4-10.4)$. The free peritoneal fluid that was sampled during surgery was an exudate.

\section{Imaging}

The chest X-ray was normal and the plain abdominal films showed dilated intestinal loop(s) in the right iliac fossa. The findings from the CT scan revealed a cystic mass of about $10 \mathrm{~cm}$ maximum diameter, located to the right, superiorly to the bladder, containing contrast material, with simultaneous 'inflammatory' infiltration (misty appearance) of the surrounding fibro-fatty tissue. A small amount of fluid at the right paracolic gutter and in the Douglas pouch was seen. The cystic appearance of the lesion was first attributed to dilated intestinal loops located close to the ileocolic area (localized ileus). An ultrasound scan of the abdomen revealed a nonhomogeneous mass located in the right iliac fossa close to the bladder, measuring $10 \mathrm{~cm}$ in maximum diameter, and showing an echo-reflective line pattern suggestive of the presence of gas in the mass lumen. No blood circulation was detected in the mass by ultrasound scanning.

\section{Working Diagnosis}

The history and clinical examination and the image findings originally led to the possible diagnosis of localized ileus, either due to sepsis from a complicated acute appendicitis forming an inflammatory mass with present dilated intestinal loops, or alternatively due to adhesions from previous surgery. 


\begin{tabular}{|c|c|c|c|}
\hline $\begin{array}{c}\text { Cose Reports in } \\
\text { incion' }\end{array}$ & $\begin{array}{l}\text { Case Rep Oncol 2009;2:7-11 } \\
\text { D0l: } 10.1159 / 000192775\end{array}$ & Published online: January 21, 2009 & \begin{tabular}{|l} 
@ 2009 S. Karger AG, Basel \\
ISSN 1662-6575 \\
www.karger.com/cro
\end{tabular} \\
\hline
\end{tabular}

Surgery

The patient underwent a laparotomy through a midline incision. A mass representing a dilated caecum with a tense and smooth wall was indentified in the right iliac fossa. A normal or acutely inflamed appendix was not recognized. Based on the experience of the surgeons, a mucocele of the appendix was suspected. Stomach, caecum and large bowel were found normal. The entire small bowel was also normal in appearance, except for the last $15 \mathrm{~cm}$ of the terminal ileum that were slightly distended. Liver and spleen were also free of any disease. The peritoneal cavity contained a small amount of inflammatory exudates. Fluid samples were taken for bacteriological examination and cytology. No uterus or ovaries were identified (previous hysterectomy). The retroperitoneal organs showed no gross abnormality. Following full examination of the peritoneal cavity, a standard right hemicolectomy was performed. The dissection of the mass off the surrounding tissue was performed fairly easily. The cystic mass remained intact during the procedure, with no leakage into the peritoneal cavity. The patient had an uneventful postoperative recovery, although it lasted for about 2 weeks due to prolonged ileus. She was discharged home 20 days after the operation in good condition, and 8 weeks later she had a colonoscopy that revealed no pathology of the entire colon and rectum.

\section{Postoperative Investigation}

Pathology

Macroscopic examination of the specimen revealed a gross dilatation of the caecal area measuring 13 $\times 12 \times 10 \mathrm{~cm}$ with abundant mucin in the lumen. Normal morphological characteristics of an appendix were not recognized. Microscopic examination showed replacement of the normal appendiceal epithelium by mucin-producing columnar glandular epithelium. The nuclei of the neoplastic cells were elongated, hyperchromatic and pseudostratified. Cellular crowding and nuclear stratification were restricted to the basal two thirds of the cells. There was no full-thickness stratification. Isolated neoplastic cells and microglandular epithelium were identified in the mucin. The muscularis propia was replaced by fibrotic, hyalinized tissue, occasionally with dystrophic calcification. Scattered residual smooth muscle fibers were seen throughout the caecal wall. No histological findings of appendiceal adenocarcinoma were identified, such as proliferation of mucinous epithelial cells with high-grade atypia, architectural complexity, or glands infiltrating a desmoplastic stroma. Twelve regional lymph nodes were found free of metastatic deposits. No clusters of malignant cells were found on the cytology specimen of the peritoneal fluid sample. The peritoneal fluid was also free of any septic flora.

\section{Discussion}

Appendiceal mucocele is a descriptive term applied to a dilated appendiceal lumen caused by abnormal accumulation of mucus. Malignant mucinous neoplasms of the appendix are rare entities. It is considered possible that such an appendiceal malignant tumor presenting as mucocele could rupture with progressive intraperitoneal accumulation of mucin, resulting in the development of pseudomyxoma peritonei. These tumors are usually clinically silent and the majority of them are discovered incidentally. When a patient presents with clinical symptoms of acute abdominal pain arising from the right iliac fossa with guarding on palpation, the diagnosis of acute appendicitis is suspected. It is also supported by the presence of a mass that is presumably the result of a locally formed inflammatory process due to appendix perforation. In the preoperative investigation, a CT and/or USS scan of the abdomen leads to the suspicion of other lesions as well, arising from other organs in the area (i.e. ovarian tumor), especially when no laboratory findings are suggestive of an acute septic intraperitoneal condition. To the patient's benefit, early operative intervention is imperative by open or laparoscopic approach [6] before a complication occurs by rupture or perforation of the appendiceal process, leading to the dissemination of contents, septic or neoplastic, resulting in the development of peritonitis, either localized or diffuse, or pseudomyxoma peritonei, respectively. 
Most authors now agree that rupture of a mucinous neoplasm (mucocele), mainly of the appendix, followed by the ovaries, would result in the development of pseudomyxoma peritonei. Preoperative recognition of a possible mucocele based on CT scan findings can be done as long as a well-encapsulated mass with smooth regular wall is seen in the right lower quadrant with no periappendiceal inflammation or abscess [7].

Pseudomyxoma peritonei is a disease entity that is characterized by a variable clinical course; if it is caused by highly aggressive appendiceal tumors, it is associated with worse clinical outcome [8]. During laparotomy the recognized massive gelatinous ascites gives the impression of disseminated and unresectable carcinomatosis, but its noninvasive nature offers significant clinical benefit by resectional surgery [9]. It is not known to date under which circumstances this complication occurs, whether by mechanically applied forces as the cystic lesion grows larger or specifically depending on the biological aggressiveness of the tumor leading to rupture of the appendix, irrespective of the size of an enlarging mucocele. Although the appendiceal mass of our patient had a tense wall, it was found to contain tenacious mucin only in the lumen of the organ that had not spilled over into the peritoneal cavity.

Our patient presented to the hospital with the warning sign of acute abdominal pain and was submitted early to laparotomy and right hemicolectomy, a procedure that offered her better chances of survival; otherwise, if a rupture of the appendiceal lesion had occurred, the life-threatening complication of pseudomyxoma peritonei would definitely have ensued. Our patient's main clinical and laboratory findings which were free of confounding homeostatic complications $[10,11]$ emphasize the potential heterogeneity of this disease entity [2] and suggest that the overall presentation and outcome of this case is likely to be characteristic, defining also a new phenotypic subset of this particular disease entity. The patient has been placed on 3 monthly follow-up examinations, and she is well 6 months postoperatively. 


\begin{tabular}{c|l|l|l}
$\begin{array}{c}\text { Cose Reports in } \\
\text { Oncolady }\end{array}$ & $\begin{array}{l}\text { Case Rep Oncol 2009;2:7-11 } \\
\text { D0I: 10.1159/000192775 }\end{array}$ & Published online: January 21, 2009 & $\begin{array}{l}\text { O 2009 S. Karger AG, Basel } \\
\text { ISSN 1662-6575 } \\
\text { www.karger.com/cro }\end{array}$ \\
\hline
\end{tabular}

Fig. 1. CT scan of the abdomen showing a mass in the right lower quadrant.

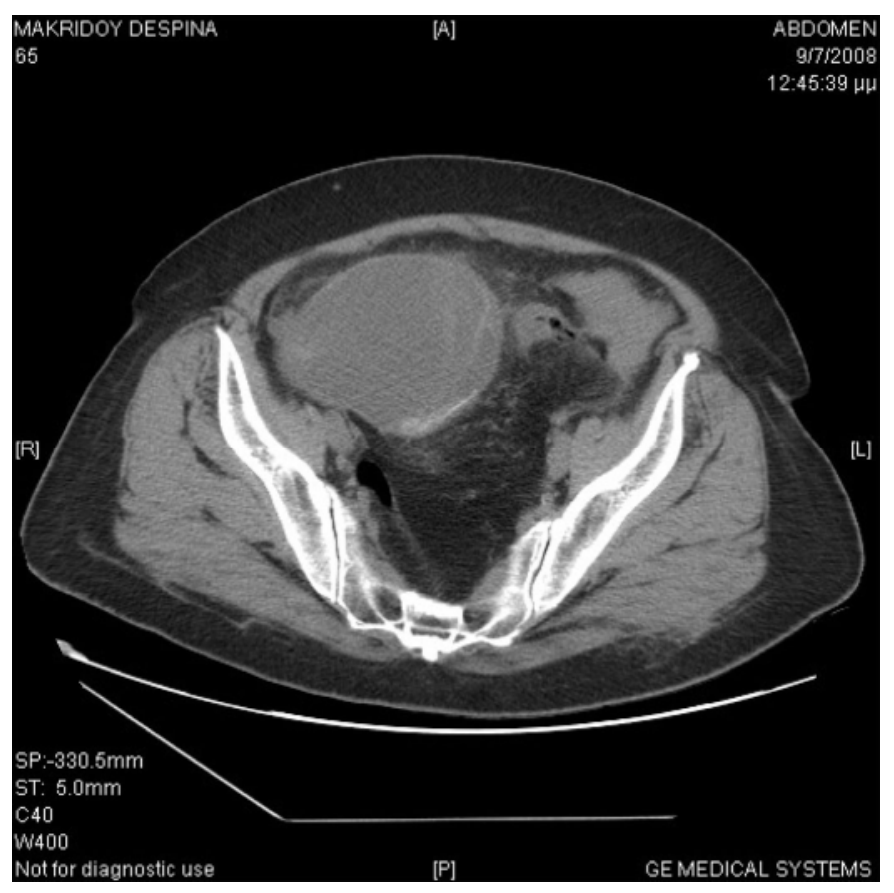




\section{References}

1 Marudanayagam R, Williams GT, Rees BI: Review of the pathological results of 2,660 appendicectomy specimens. J Gastroenterol 2006;41:745-749.

2 Misdraji J, Yantiss RK, Graeme-Cook FM, Balis UJ, Young RH: Appendiceal mucinous neoplasms: a clinicopathologic analysis of 107 cases. Am J Surg Pathol 2003;27:1089-1103.

-3 Bradley RF, Stewart JH 4th, Russell GB, Levine EA, Geisinger KR: Pseudomyxoma peritonei of appendiceal origin: a clinicopathologic analysis of 101 patients uniformly treated at a single institution, with literature review. Am J Surg Pathol 2006;30:551-559.

-4 Lee J, Gardiner KR, Wilson BG: Incidental mucinous cystadenocarcinoma of the appendix. Postgraduate Med J 1996;72:55-56.

5 Ruiz-Tovar J, Teruel DG, Castineiras VM, Dehesa AS, Quindos PL, Molina EM: Mucocele of the appendix. World J Surg 2007;31:542-548.

-6 Palanivelu C, Rangarajan M, John SJ, Senthilkumar K, Annapoorni S: Laparoscopic right hemicolectomy for mucocele due to a low-grade appendiceal mucinous neoplasm. JSLS 2008;12:194-197.

7 Madwed D, Mindelzun R, Jeffrey RB Jr: Mucocele of the appendix: imaging findings. AJR Am J Roentgenol 1992;159:69-72.

-8 Maheshwari V, Tsung A, Lin Y, Zeh HJ 3rd, Finkelstein SD, Bartlett DL: Analysis of loss of heterozygosity for tumor-suppressor genes can accurately classify and predict the clinical behavior of mucinous tumors arising from the appendix. Ann Surg Oncol 2006;13:1610-1616.

\9 Smith JW, Kemeny N, Caldwell C, Banner P, Sigurdson E, Huvos A: Pseudomyxoma peritonei of appendiceal origin. Cancer 1992;70:396-401.

10 Vamvakopoulos NV: Sexual dimorphism of stress response and immune/inflammatory reaction: the corticotropin releasing hormone perspective. Mediators Inflamm 1995;4:163-174.

-11 Nomikos I, Kalogerakos K, Athanassiou E, Plakokefalos E, Sioutopoulou D, Satra $\mathrm{M}$, Vamvakoploulos $\mathrm{N}$ : Role of hyperglycemia in isogeneic islet transplantation: an experimental animal study. Exp Clin Endocrinol Diabetes 2008;116:558-560. 